\title{
Neutropenia with Multiple Antipsychotics Including Dose Dependent Neutropenia with Lurasidone
}

\author{
Shabnam Sood \\ Maricopa Integrated Health System/District Medical Group, University of Arizona School of Medicine, Phoenix, AZ, USA
}

\begin{abstract}
Antipsychotic-induced agranulocytosis is a significant side effect that is known to occur with most of the antipsychotic medications. It usually resolves once the medications are stopped and patients are able to be switched over to another antipsychotic medication. Lurasidone has not been reported to cause leukopenia and neutropenia. This case report is of a patient with a past history of risperidone induced-aganulocytosis developing dose related leukopenia and neutropenia with lurasidone.
\end{abstract}

KEY WORDS: Lurasodone; Typical antipsychotics; Atypical antipsychotics.

\section{INTRODUCTION}

Antipsychotic medication-induced agranulocytosis is a significant side effect that is best known in relation to clozapine. ${ }^{1)}$ It is known to occur with most of the antipsychotic medications $^{2)}$; aripiprazole, olanzapine, paliperidone, quetiapine, risperidone and ziprasidone. It usually resolves once the medications are stopped and patients are then switched over to another antipsychotic medication. $^{3)}$

\section{CASE}

The patient is a 41-year-old single African American male who was admitted on an involuntary petition after having been found walking on the streets, moving traffic barricades and directing traffic. On admission, he presented with marked paucity of thought, flat affect, paranoia, auditory hallucinations and impairments in recent memory, and he was not oriented to time or place. No significant substance use was present and his only medical problem was hypertension.

He had a long history of schizophrenia since his 20 s and has had multiple admissions with prior court ordered treat-

\footnotetext{
Received: August 22, 2016 / Revised: October 11, 2016

Accepted: October 12, 2016

Address for correspondence: Shabnam Sood, MD

Desert Vista Behavioral Health Center, 570 West Brown Road,

Mesa, AZ 85201, USA

Tel: +1-480-344-2003, Fax: +1-480-344-2014

E-mail: shabnam_sood@dmgaz.org
}

ment due to non-adherence with medications. His past history was significant for cognitive deficits and he has had trials of several antipsychotics including haloperidol, fluphenazine, risperidone, aripiprazole and ziprasidone. During a past admission one year ago, he had developed neutropenia with risperidone, resulting in a white blood cell (WBC) count dropping from $6.0 \times 10^{3}$ to $3.6 \times 10^{3} / \mu 1$. A complete work up was done to rule out other causes for neutropenia. Once the WBC count improved, he was treated with haloperidol with blood counts in the normal range. The patient was discharged with improvement in psychosis, but memory impairments persisted. As an outpatient, he was non-adherent with medications and had been off the haloperidol for several months prior to this admission.

During the course of this most recent admission, the patient was started on haloperidol $5 \mathrm{mg}$ twice a day and the dose increased to a total of $15 \mathrm{mg}$. His WBC was $3.8 \times 10^{3} / \mu 1$ and he had an absolute neutrophil count (ANC) of $1.8 \times 10^{3} / \mu \mathrm{l}$ (reference range, $1.6 \times 10^{3}-9.2 \times 10^{3} / \mu \mathrm{l}$ ) on admit, which was on the low side of normal but normal for the African American ethnicity. WBC and ANC dropped to $3.6 \times 10^{3} / \mu 1$ and $1.2 \times 10^{3} / \mu 1$ respectively on day 8 . The haloperidol was decreased to $5 \mathrm{mg}$ twice a day and the ANC dropped further to $1.1 \times 10^{3} / \mu 1$ on day 13 , while the WBC stayed the same. Haloperidol was stopped and the ANC improved on day 17 to $2.4 \times 10^{3} / \mu 1$. Lurasidone was initiated at $20 \mathrm{mg}$ and the dose increased to $40 \mathrm{mg}$. On day 23, his WBC improved to $5.1 \times 10^{3} / \mu 1$ and ANC to $2.4 \times 10^{3} / \mu 1$, and the dose of lurasidone increased to $80 \mathrm{mg}$. The patient

(c) This is an Open-Access article distributed under the terms of the Creative Commons Attribution Non-Commercial License (http://creativecommons.org/licenses/by-nc/4.0) which permits unrestricted non-commercial use, distribution, and reproduction in any medium, provided the original work is properly cited. 
Table 1. Clinical course

\begin{tabular}{clccc}
\hline Day & Medication & $\begin{array}{c}\text { Dose } \\
(\mathrm{mg})\end{array}$ & $\begin{array}{c}\text { WBC } \\
\left(\times 10^{3} / \mu \mathrm{l}\right)\end{array}$ & $\begin{array}{c}\text { ANC } \\
\left(\times 10^{3} / \mu \mathrm{l}\right)\end{array}$ \\
\hline 1 & Haloperidol & 10 & 3.8 & 1.8 \\
8 & & 15 & 3.6 & 1.2 \\
13 & & 10 & 3.6 & 1.1 \\
14 & Haloperidol stopped & & & \\
17 & No medication & & & 2.4 \\
18 & Lurasidone & 20 & & \\
20 & & 40 & & \\
23 & & 40 & 5.1 & 2.4 \\
24 & & 80 & & \\
29 & & 60 & 3.1 & \\
33 & & 120 & & \\
37 & & 120 & 4.0 & 1.4 \\
38 & & 80 & & \\
43 & & 80 & 4.6 & 1.8 \\
\hline
\end{tabular}

WBC, white blood cell; ANC, absolute neutrophil count.

had a decrease in auditory hallucinations but the cognitive impairments persisted, for which a brain magnetic resonance imaging was done and no abnormalities were found. WBC counts and the ANC continued to improve with increase to $6.0 \times 10^{3} / \mu 1$ and $3.1 \times 10^{3} / \mu$ l on day 29 . Lurasidone was increased on day 33 to $120 \mathrm{mg}$, and blood draw on day 37 showed a drop in WBC to $4.0 \times 10^{3} / \mu 1$ and ANC to $1.4 \times 10^{3} / \mu 1$. The dose of lurasidone was decreased back down to $80 \mathrm{mg}$ and blood counts repeated on day 43 showed an improvement with $\mathrm{WBC}$ at $4.6 \times 10^{3} / \mu 1$ and ANC at $1.8 \times 10^{3} / \mu \mathrm{l}$ (Table 1 ). The patient was maintained at that dose and showed a decrease in psychosis and was transferred to a sub-acute facility, until proper housing could be found for him. During the hospital course, he was not given any other antipsychotic medications, did not develop any signs of infection and his liver function tests stayed within normal limits.

\section{DISCUSSION}

Agranulocytosis is less likely to occur with the first generation or typical antipsychotic medications than second generation or atypical antipsychotics. A German Arzneimittelüberwachung in der Psychiatrie (AMÜP; drug monitoring in psychiatry) study ${ }^{4)}$ reporting adverse drug reactions found six cases of agranulocytosis induced by perazine and significant leukocytosis occurring in seven other cases - four involving butyrophenones and three involving phenothiazines. In addition, there has been one case reported with haloperidol monotherapy causing neutropenia in an elderly patient ${ }^{5)}$ and another with a combination of thiothexine and haloperidol. ${ }^{6}$ There has been one report of luradisone and neutropenia in the grey literature $^{7)}$ but no reported case of lurasidone causing agranulocytosis in scientific journals. The patient had developed agranulocytosis with risperidone, so haloperidol, a medication he had tolerated well in the past, was considered a safer medication, given his history of non-adherence and the need to start a long-acting depot injection. On this admission, he developed agranulocytosis with haloperidol. He had no medical problems, liver damage, infections or blood dyscrasias to account for it. His WBC counts quickly returned to normal levels once the offending agent was discontinued. Lurasidone was chosen, given his propensity to develop agranulocytosis, and he was able to tolerate doses of up to $80 \mathrm{mg}$ a day with no side effect. Increasing the dose to $120 \mathrm{mg}$ caused a decrease in his total WBC counts and the neutrophil counts which reversed with the lower $80 \mathrm{mg}$ dose.

Cases of patients developing aganulocytosis with multiple antipsychotic medications are not common. Although in one case report, a patient developed agranulocytosis with four antispychotic medications (olanzapine, quetiapine, risperidone and aripiprazole) ${ }^{8)}$ and in another with three antipsychotics (quetiapine, olanzapine, and aripiprazole), ${ }^{9)}$ patients were able to be successfully switched to a different antipsychotic medication. Immunological mechanisms $^{10)}$ are likely important in patients who develop repeated episodes of neutropenia. Dose related component has been reported for clozapine. ${ }^{11)}$ Patients who have history of neuroleptic induced agranulocytosis or neutropenia should be carefully monitored for WBC counts and signs of infections.

\section{REFERENCES}

1. Stephens P. A review of clozapine: an antipsychotic for treatment-resistant schizophrenia. Compr Psychiatry 1990; 31:315-326.

2. Rettenbacher MA, Hofer A, Kemmler G, Fleischhacker WW. Neutropenia induced by second generation antipsychotics: a prospective investigation. Pharmacopsychiatry 2010;43:41-44.

3. Coşar B, Taner ME, Eser HY, Altınöz AE, Tarhan R. Does switching to another antipsychotic in patients with clozapine-associated granulocytopenia solve the problem? Case series of 18 patients. J Clin Psychopharmacol 2011; 31:169-173.

4. Grohmann R, Schmidt LG, Spiess-Kiefer C, Rüther E. Agranulocytosis and significant leucopenia with neuroleptic drugs: results from the AMUP program. Psychopharmacology (Berl) 1989;99 Suppl:S109-S112.

5. Jurivich DA, Hanlon J, Andolsek K. Neuroleptic-induced neutropenia in the elderly. J Am Geriatr Soc 1987; 35:248-250.

6. Cutler NR, Heiser JF. Leukopenia following treatment with thiothixene and haloperidol. JAMA 1979;242:2872-2873. 
7. Review: could Latuda cause Neutropenia? [Internet]. Mountain View, CA: eHealthMe; 2017 [cited at $2016 \mathrm{Apr}$ 20]. Available from http://www.ehealthme.com/ds/latuda/ neutropenia.

8. Lim MH, Park JI, Park TW. A case with neutropenia related with the use of various atypical antipsychotics. Psychiatry Investig 2013;10:428-431.

9. Lander M, Bastiampillai T. Neutropenia associated with quetiapine, olanzapine, and aripiprazole. Aust $N Z J$
Psychiatry 2011;45:89

10. Singh A, Grover S, Malhotra P, Varma SC. Late onset agranulocytosis with clozapine associated with HLA DR4 responding to treatment with granulocyte colony-stimulating factor: a case report and review of literature. Clin Psychopharmacol Neurosci 2016;14:212-217.

11. Flanagan RJ, Dunk L. Haematological toxicity of drugs used in psychiatry. Hum Psychopharmacol 2008;23 Suppl 1:27-41. 